ARTICLE

https://doi.org/10.1057/s41599-019-0302-1

\title{
Rural unemployment pushes migrants to urban areas in Jiangsu Province, China
}

\author{
Haoyang Lyu ${ }^{1,2}$, Zengchuan Dong ${ }^{2}$, Mahendran Roobavannan ${ }^{3}$, Jaya Kandasamy ${ }^{3} \&$ Saket Pande ${ }^{1}$
}

\begin{abstract}
Migration is often seen as an adaptive human response to adverse socioenvironmental conditions, such as water scarcity. A rigorous assessment of the causes of migration, however, requires reliable information on the migration in question and related variables, such as, unemployment, which is often missing. This study explores the causes of one such type of migration, from rural to urban areas, in the Jiangsu province of China. A migration model is developed to fill a gap in the understanding of how rural to urban migration responds to variations in inputs to agricultural production including water availability and labor and how rural population forms expectations of better livelihood in urban areas. Rural to urban migration is estimated at provincial scale for period 1985-2013 and is found to be significantly linked with rural unemployment. Further, migration reacts to a change in rural unemployment after 2-4 years with 1\% increase in rural unemployment, on average, leading to migration of 16,000 additional people. This implies that rural population takes a couple of years to internalize a shock in employment opportunities before migrating to cities. The analysis finds neither any evidence of migrants being pulled by better income prospects to urban areas nor being pushed out of rural areas by water scarcity. Corroborated by rural-urban migration in China migration survey data for 2008 and 2009, this means that local governments have 2-4 years of lead time after an unemployment shock, not necessarily linked to water scarcity, in rural areas to prepare for the migration wave in urban areas. This original analysis of migration over a 30-year period and finding its clear link with unemployment, and not with better income in urban areas or poor rainfall, thus provides conclusive evidence in support of policy interventions that focus on generating employment opportunities in rural areas to reduce migration flow to urban areas.
\end{abstract}

\footnotetext{
${ }^{1}$ Department of Water Management, Delft University of Technology, 2628CN Delft, Netherlands. ${ }^{2}$ College of Hydrology and Water Resources, Hohai University, Nanjing, China. ${ }^{3}$ School of Civil and Environmental Engineering, Faculty of Engineering and Information Technology, University of Technology Sydney, PO BOX 123 Broadway, Sydney, Australia. Correspondence and requests for materials should be addressed to S.P. (email: s.pande@tudelft.nl)
} 


\section{Introduction}

B etter understanding of linkages between water scarcity and migration is needed in the debate of whether migration is an adaptive strategy or a nonbeneficial struggle of humans under climate variability and change (Lilleør and Van den Broeck, 2011; Tacoli, 2009; Yan and Shi, 2017). The consequences of migration are two-sided. On one hand it helps migrants to find more suitable livelihood, on the other hand it causes overpopulation and excessive competition in large cities, and even conflicts between migrants and prior residents over public goods such as water, sanitation, and hygiene (Li, 2010, 2005). Even if migrants are able to earn and consume more in urban areas, their subjective well-being might be worse due to weak or nonexistent social networks (Chen et al., 2019; Knight and Gunatilaka, 2010; Akay et al., 2012). The continuous migration from less-developed rural areas to cities causes an "Empty Nest" problem, which occurs when young adults leave their families in rural areas, leaving behind the very old (Chen, 2009; Yao, 2006), the very young (Duan and Zhou, 2005; Zhou and Duan, 2006), and the socially vulnerable.

Urbanization patterns in developing countries, such as rural-urban migration in sub-Saharan Africa, appear to have been influenced by climate variability (Barrios et al., 2006; McLeman and Hunter, 2010). Yu et al. (2011) revealed a similar pattern in southwest China, where a significant rural to urban migration occurred apparently in response to an extreme drought from August to September 2010. Environmental changes are therefore often seen as one of the drivers of migration (Black et al., 2011), but other drivers such as economic production and employment are equally linked with poverty and migration (Pande et al., 2014; Wang and Luo, 2014), rendering the relationship between environmental extremes, such as flood and droughts, and migration unclear (Gray and Mueller, 2012). Economic opportunities have been recognized as fundamental drivers to nonpermanent migration (Wang, 2017), irrespective of the scale of migration. Links between employment opportunities and rural-urban migration at national scale have been reported in countries such as China, Senegal, Bangladesh and India (Goldsmith et al., 2004; Zhang and Shunfeng, 2003; Zhao, 1999; Munshi and Rosenzweig, 2016). For example, both skilled and nonskilled labor tend to migrate from interior regions of China to its coast. However, the migration of skilled labor appears to be less influenced by the regional unemployment rate and concentration of foreign investment and more by regional wage disparity (Liu and Shen, 2017). Thomas (1973) even found linkages between out-migration and economic growth of Britain with cross-Atlantic economies.

Unemployment influences regional labor migration because an unemployed worker is more likely to move with regional unemployment differentials encouraging such mobility (Pissarides and Wadsworth, 1989). Even though rural-urban migration might negatively influence urban employment (Chen, 2007), rural migrants are often driven by their expectation of improved employment or earnings and desire to urbanize (Glomm, 1992; Mabogunje, 1970; Todaro, 1969). Such aspirations of better lives in urban areas are based on household level decisions to either maximize expected income or minimize risk that the household is exposed to by diversifying the portfolio of income-generating activities (Chen et al., 2019; Akay et al., 2012; Massey et al., 1993). Such decisions to migrate are based on experienced utility, but are often limited by substantial social and economic barriers (Chen at al., 2019; Bryan et al., 2014). As a result, it is often the individuals from households that are at above-average incomes that migrate (Knight and Gunatilaka, 2010). The effect of natural disasters such as droughts and flooding can therefore be ambiguous (Gray and Mueller, 2012; Chen et al., 2017). On one hand, it can reduce migration by removing resources necessary for migration to overcome setup costs or increasing labor demand in originating areas, while in some other cases it may reduce all possible income-generating possibilities, pushing migrants in masses out of affected areas (Chen et al., 2017). Such "push" factors contrast the "pull" factors of big city dreams or explicit solicitation campaigns by employers in urban areas (Massey et al., 1993).

Rural-to-urban migration is a well-observed phenomenon in China. For example, Zhao (1999) found that migration decisions in China are based on economic factors (shortage of farmland and rural taxation), although a lack of stable returns from employment in urban areas has slowed down permanent migration (Zhao, 1999). Zhang and Shunfeng (2003) reported similar links between rural-urban migration in China (RUMiC) during 1978-1999 and attributed it to economic growth, especially in highly urbanized coastal areas (Zhang and Shunfeng, 2003). This paper investigates rural-urban migration in one such case, and inquires whether it is driven by water availability, rural unemployment, or urban employment at higher wages. Jiangsu is a province with a strong economy in urban areas and one of the highest population densities. Its rural population continues to shrink as urban areas expand (Bureau of Statistics of Jiangsu, 1987-2016; Xu, 2009; Liu et al., 2010). For example, Liu et al. (2010) reported a significant $21.6 \%$ ( $>10$ million) of the population with rural registration that emigrated from rural areas in Jiangsu in 2005 and 2006, mostly originated from northern Jiangsu and relocated to its more urbanized southern parts (Chen, 2007; Huang, 2006; Wang, 2017; Zhang and Huang, 2009).

Understanding the drivers of migration demands its analysis over an extended period. This is challenging in absence of migration-related household surveys such as RUMiC 2008 and 2009 (China Institute For Income Distribution, Beijing Normal University, 2019). Section "Methodology" therefore first presents methodologies to estimate a time series of rural to urban migration in Jiangsu, rural labor demand and the rural-urban unemployment rate gradient from 1985 to 2015. It then interprets migration in terms of unemployment and income. Section "Rural-urban net migration" presents the data analysis, which includes the estimated migration time series and analysis of other data sets used such as the time series of inputs to agricultural production in Jiangsu province. Section "Modeling results" presents the results that are further discussed in the next section. The last section summarizes the conclusions.

\section{Methodology}

Study area. The Jiangsu province is relatively developed with a strong economy and high population density within the economic belt of the Yangzi River. Located in a subtropical and humid area with more than $1000 \mathrm{~mm}$ of precipitation per year, the Jiangsu province has abundant water resources and a complex hydrological system, represented by the river network of the Taihu Lake system in the downstream area of the Yangzi River Basin (Fig. 1). Jiangsu is a producer of crops such as rice and wheat, which occupy $58.4 \%$ of the total plant area in 2016 . Agriculture production is closely linked to water availability and is influenced by climatic factors. Mechanization and technology uptake further contribute to agriculture output. In 2016, the total power of agricultural machinery reached $4.906 \times 10^{7} \mathrm{KW}$, bringing the mechanization level to $82 \%$. Preferential policies such as agricultural support and protection subsidies have also supported farmers. These government initiatives have produced rapid development and industrialization of agriculture in Jiangsu. At the same time, Jiangsu is undergoing an industrial revolution. The proportion of agriculture output is being gradually reduced by 


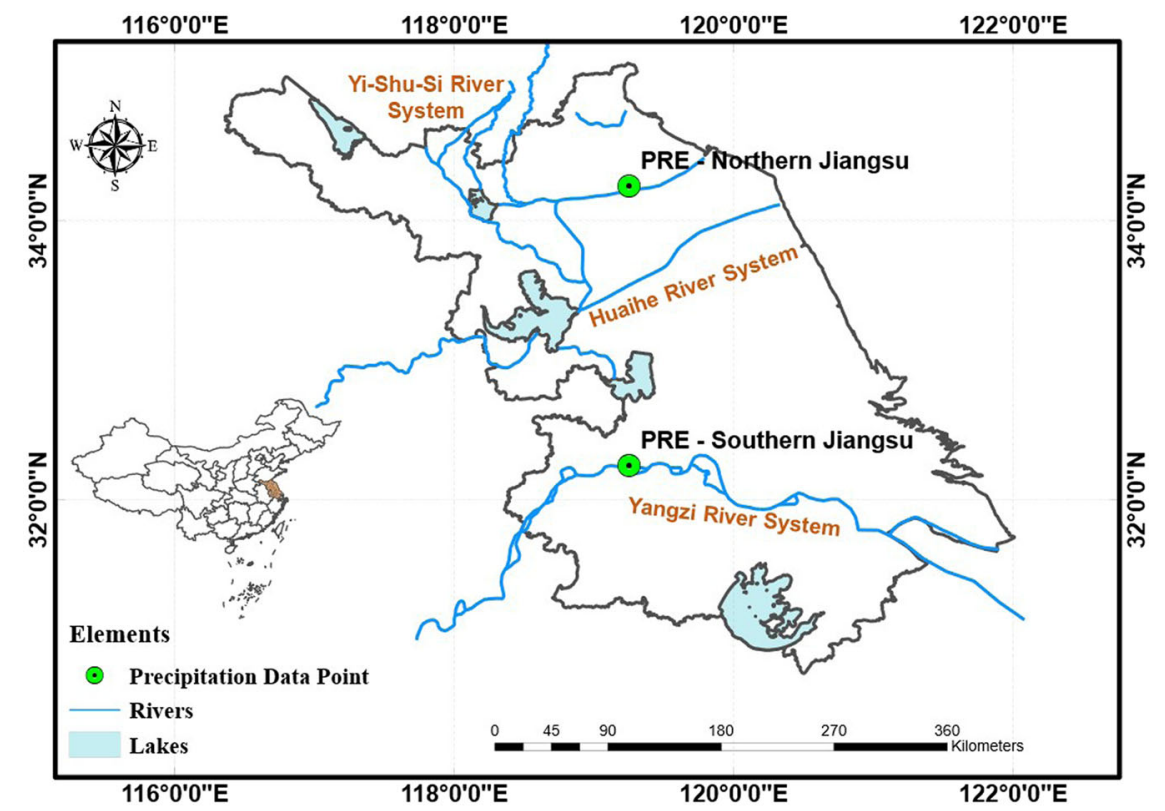

Fig. 1 Jiangsu province. Also shown are locations of the two precipitation stations used to estimate precipitation anomalies (PRE Point-Northern Jiangsu, PRE Point-Southern Jiangsu)

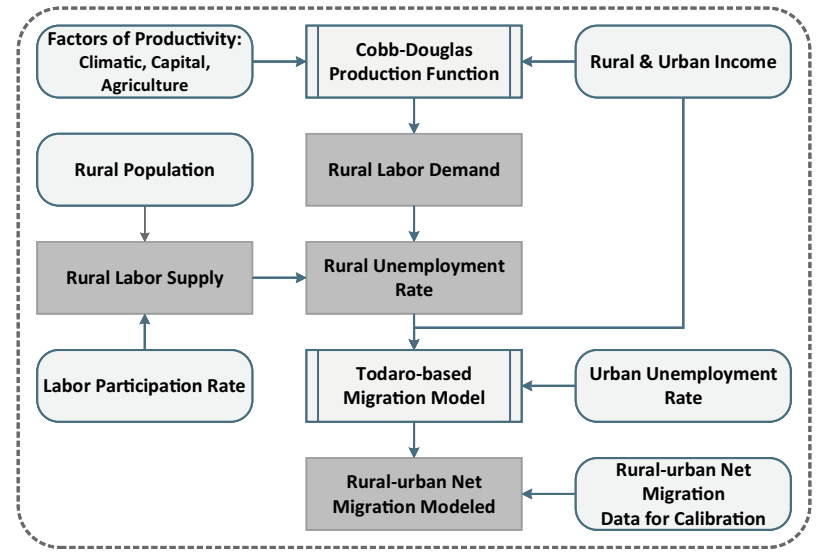

Fig. 2 The framework of rural-urban migration analysis. Boxes with curved corners indicate input data. Estimated unemployment rate and rural to urban migration are analyzed

modern secondary and tertiary industries. Nonagricultural sectors add to the income sources of rural families. Agricultural mechanization has reduced labor demand, while farm workers have become employed in modern industries (Fig. 2).

Methodology. The interpretation and simulation of rural-urban net migration is inspired by the Todaro model (Todaro, 1969), which was originally developed to understand labor transfer between traditional (e.g., in rural areas) and modern (e.g., in urban areas) sectors of an economy. The Todaro model interprets the transfer of labor as an increasing function of expected difference between the traditional and modern sector incomes, which we show can be dominated by the difference in unemployment rates. Unemployment rates in urban areas are obtained from the data of the Statistical Bureau of Jiangsu (Bureau of Statistics of Jiangsu, 1987-2016) and used since the labor markets in urban areas are more formally monitored and managed by the government. By contrast, the unemployment rate in rural areas cannot be directly measured because of the nature of agricultural employment in China. There is no clear boundary between the "employed" and "unemployed" farmers because every person in a household can work on household farms in some form. Therefore, we first estimate the rural agricultural labor demand using the Cobb-Douglas production function, and then represent the unemployment rate in rural agricultural sectors as the ratio of surplus labor to employable (or available) labor supply (following Roobavannan et al., 2017a, b). In this way, underemployed individuals that are not efficiently employed in rural areas are also counted as unemployed.

Estimation of net rural-urban migration. The rural-urban net migration data series has been estimated based on the population dataset from the Statistical Yearbook of Jiangsu (1987-2016) (Bureau of Statistics of Jiangsu, 1987-2016), that includes total population, rural population, and total natural population growth.

If we set the total population of the province at time step $t$ as $\Phi_{T}(t)$, rural population as $\Phi_{R}(t)$, natural total population growth (the difference between total birth and death rate) as $\Delta \Phi_{N T}(t)$ then urban population $\Phi_{U}(t)$ is obtained by

$$
\Phi_{U}(t)=\Phi_{T}(t)-\Phi_{R}(t) .
$$

We focus on analyzing the source of urban population net growth, which is calculated as

$$
\Delta \Phi_{U}(t)=\Phi_{U}(t)-\Phi_{U}(t-1) .
$$

We assume that the natural population growth rate is the same in urban and rural areas. For example, the difference between rural and urban areas in birth rate is of the order of no more than 2.49\% for years 1985-1990 (Jiangsu Provincial Local Chronicle Compilation Committee, 1999). Note that is based on the reported urban-county birth rate difference, which Jiangsu Provincial Local Chronicle Compilation Committee (1999) has suggested to be a good approximation of urban-rural birth rate difference. Given that the rural mortality rate is usually higher than that of urban areas, the gap between rural and urban natural growth rate would be even smaller. Also, referring to a population simulation by Shen and Spence (1996) and our sensitivity analysis of the model, the gap between rural and urban natural growth rates in Jiangsu from 1980s to 2010s should be relatively stable 
and $<3 \%$. Therefore we let natural growth rate in urban areas, $\frac{\Delta \Phi_{N U}(t)}{\Phi_{U}(t)}$, to be equal to the natural growth rate of the province, $\frac{\Delta \Phi_{N T}(t)}{\Phi_{T}(t)}$. The natural growth rate for urban areas, $\Delta \Phi_{N U}(t)$, is obtained as

$$
\Delta \Phi_{N U}(t)=\Delta \Phi_{N T}(t) \frac{\Phi_{U}(t)}{\Phi_{T}(t)} .
$$

With the total population net growth and natural population growth, we can calculate the "un-natural" population growth in urban areas, $\Delta \Phi_{U N U}(t)$, which is migration from rural areas and from other regions outside the province.

$$
\Delta \Phi_{U N U}(t)=\Delta \Phi_{U}(t)-\Delta \Phi_{N U}(t)
$$

We also assume that net migration from outside of the province (foreign migration), $\mu_{F}(t)$, moves toward urban areas of Jiangsu. The assumption is based on the observation that nearly $80 \%$ of the foreign migrants moved to urban areas within Jiangsu province during 1985-1990 (Jiangsu Provincial Local Chronicle Compilation Committee, 1999). The main trend in rural Jiangsu is emigration (Liu et al., 2010). Thus, the destination of migrants from outside of the province can safely be assumed to be urban areas.

Since the unnatural growth rate of urban areas is the sum of foreign migration, $\mu_{F}(t)$, from outside Jiangsu and rural-urban migration within Jiangsu, $\mu_{R U}(t)$, the rural-urban net migration can be given as

$$
\mu_{R U}(t)=\Delta \Phi_{U N U}(t)-\mu_{F}(t)
$$

Here foreign migration rate, $\mu_{F}(t)$, because it comes from outside Jiangsu, is given by

$$
\mu_{F}(t)=\Delta \Phi_{T}(t)-\Delta \Phi_{N T}(t)
$$

and

$$
\Delta \Phi_{T}(t)=\Phi_{T}(t)-\Phi_{T}(t-1) .
$$

Labor demand. The demand for labor in both agricultural and nonagricultural sectors within rural areas of Jiangsu determines the employment rate. This section discusses how labor demand is estimated.

Cobb-Douglas production function. The Cobb-Douglas production function has been applied to describe the evolution of labor demand in rural agricultural and nonagricultural sectors, which are driven by various factors of production. The Cobb-Douglas production function links the output of an industry with different inputs, which are usually categorized into labor and capital. The original equation of Cobb-Douglas production (Cobb and Douglas, 1928) is shown as below

$$
Y_{j}=A_{j} K_{j}^{\alpha} L_{j}^{\beta} \text {. }
$$

Where $Y_{j}$ is the total output of industry $j ; A_{j}$ is the total factor productivity of industry $j ; K_{j}$ is capital input of industry $j ; L_{j}$ is labor input of industry $j$. Also, $\alpha$ and $\beta$ are output elasticities of capital and labor, which are in the form of exponential weights such that $\alpha+\beta=1$.

To incorporate more driving factors (inputs), we use a more generalized form of the Cobb-Douglas production function, in the form of Eq. (6b), with $n$ driving factors $F_{j 1}, \ldots, F_{j i}, \ldots, F_{j n}$ (including labor) and associated elasticities $\alpha_{1}, \ldots, \alpha_{i}, \ldots, \alpha_{n}$.

$$
Y_{j}=A_{j} \prod_{i=1}^{n} F_{j i}^{\alpha_{i}}
$$

For $\alpha_{i}$, we have

$$
\sum_{i=1} \alpha_{i}=1
$$

To distinguish the variable "Labor" from other factors, we set "Labor" $F_{j n}$ as $L_{j}$ with $\alpha_{n}$, then Eq. (6b) turns into the form of

$$
Y_{j}=A_{j} \prod_{i=1}^{n-1} F_{j i}^{\alpha_{i}} L_{j}^{\alpha_{n}} .
$$

With

$$
\alpha_{n}=1-\sum_{i=1}^{n-1} \alpha_{i} .
$$

Labor wage is set equal to the marginal value of labor, and then assumed to be equal to income per unit labor.

$$
w_{j}=\frac{\partial Y_{j}}{\partial L_{j}}=\frac{M_{j}}{L_{j}}
$$

The incomes, $M_{j}$, of both agricultural and nonagricultural sectors are associated with corresponding outputs that they generate using labor wage as an intermediary. We therefore assume that labor is allocated efficiently to agricultural and nonagricultural production. To obtain the equation for estimating labor demand $L_{j}$, we first calculate the growth rate of labor wage $w_{j}$.

$$
\begin{gathered}
w_{j}=\frac{\partial Y_{j}}{\partial L_{j}}=\left(1-\sum_{i=1}^{n-1} \alpha_{i}\right) \frac{A_{j} \prod_{i=1}^{n-1} F_{j i}^{\alpha_{i}}}{\sum_{j}^{n-1} \alpha_{i}} \\
\frac{\dot{w}_{j}}{w_{j}}=\frac{\dot{A}_{j}}{A_{j}}+\sum_{i=1}^{n-1} \alpha_{i} \frac{\dot{F}_{j i}}{F_{j i}}-\frac{\dot{L}_{j}}{L_{j}} \sum_{i=1}^{n-1} \alpha_{i}
\end{gathered}
$$

Then, $w_{j}$ is replaced by $\frac{M_{j}}{L_{j}}$ in Eq. (8a) to obtain an expression for labor demand growth rate $\frac{\dot{L}_{j}}{L_{j}}$.

$$
\begin{aligned}
& \frac{\dot{M}_{j}}{M_{j}}-\frac{\dot{L}_{j}}{L_{j}}=\frac{\dot{A}_{j}}{A_{j}}+\sum_{i=1}^{n-1} \alpha_{i} \frac{\dot{F}_{j i}}{F_{j i}}-\frac{\dot{L}_{j}}{L_{j}} \sum_{i=1}^{n-1} \alpha_{i} \\
& \frac{\dot{L}_{j}}{L_{j}}=\frac{\frac{\dot{A}_{j}}{A_{j}}+\sum_{i=1}^{n-1} \alpha_{i} \frac{\dot{F}_{j i}}{F_{j i}}-\frac{\dot{M}_{j}}{M_{j}}}{\sum_{i=1}^{n-1} \alpha_{i}} \cdot\left(1-\frac{1}{\sum_{i=1}^{n-1} \alpha_{i}}\right)^{-1}=\frac{\frac{\dot{A}_{j}}{A_{j}}+\sum_{i=1}^{n-1} \alpha_{i} \frac{\dot{F}_{j i}}{F_{j i}}-\frac{\dot{M}_{j}}{M_{j}}}{\sum_{i=1}^{n-1} \alpha_{i}-1}
\end{aligned}
$$

With the growth rate of labor demand and an initial value of $L_{0}$, a complete time series of labor demand for industry $j$ can be obtained recursively as shown below

$$
L_{j}(t)=L_{j}(t-1)\left(\frac{\dot{L}_{j}}{L_{j}}(t)+1\right)
$$

\section{Factors of production}

Rural agricultural production. We set six factors of production (including labor) as inputs to agricultural production in Jiangsu Province, China. These are labor, plant area, water availability (here represented by precipitation), fertilizer, machinery, and pesticide. The shares of agricultural inputs (or elasticities) are based on Sun et al. (2008) and shown in Table 1. Among the factors selected by Sun et al. (2008), irrigated area was chosen to represent the influence of water availability during agricultural production. We use annual precipitation as the proxy of water input, which then includes not only irrigated but also rainfed agriculture. The precipitation influences the estimated agricultural labor demand since water is one important input to agricultural production.

Rural non-agricultural production. For the nonagricultural sector, two driving factors (inputs) of output, which are labor and gross 
Table 1 Elasticities of factors of agricultural production

\begin{tabular}{|c|c|c|c|c|c|c|c|}
\hline Factors & Labor & Plant area & Precipitation & Fertilizer & Machinery power & Pesticide & Total \\
\hline Share & 0.534 & 0.252 & 0.051 & 0.090 & 0.059 & 0.014 & 1.000 \\
\hline
\end{tabular}

capital formation (represents the capital input for nonagricultural production) (National Bureau of Statistics of China, 2016), are used to model the temporal evolution of labor demand of the rural nonagricultural sector. A two-factor version of the Cobb-Douglas production function in Eq. (8c) is used. Data sources related to rural nonagricultural production are listed in Table S1.

Unemployment driven net migration. Similar to Todaro (1969), we assume that transfer of labor from rural to urban sectors, $\tau_{\mathrm{U}}(t)$, per unit labor supply, $S_{U}(t)$, can be linked to expectations of future net income that people form in rural and urban areas ( $V_{U}(t)$ and $V_{R}(t)$, respectively). The hypothesized relationship is expressed via the equation below

$$
\frac{\tau_{U}}{S_{U}}(t)=F\left(\frac{V_{U}(t)-V_{R}(t)}{V_{R}(t)}\right)
$$

Where $F[$.$] is an increasing function with F>0 . V_{U}(t)$ is the discounted present value of the expected urban real income stream over time $t^{\prime}, \bar{Y}_{U}\left(t^{\prime}\right)$, from the present (at time $t$ ) to a distant future. $V_{R}(t)$ is the discounted present value of the expected rural real income stream $\bar{Y}_{R}\left(t^{\prime}\right)$. Equation (10a) suggests that transfer of labor from rural to urban sectors increases as the difference between expected income streams of urban and rural sector increases relative to rural income.

We here note that a decision to migrate is costly for rural labor yet it is motivated by their expectation of future income. The latter is known to be based on subjective probabilities, which often depends on turning points of income in the past (Fisher, 1962; Schmalensee, 1976). This means that expectations of future income streams, which rural labor form, may rely on some significant income changes in the past. We assume that a population forms its discounted expectation of future income stream based on average income across population that people

observe $\quad V_{U}(t)=\bar{Y}_{U}(t-\ell)=\left[1-U_{U}(t-\ell)\right] Y_{U}(t-\ell)$ years

$$
V_{R}(t)=\bar{Y}_{R}(t-\ell)=\left[1-U_{R}(t-\ell)\right] Y_{R}(t-\ell) .
$$

in the past. Given that the average income in the past is income realized conditioned on being employed, we have

$$
\begin{aligned}
& V_{U}(t)=\bar{Y}_{U}(t-\ell)=\left[1-U_{U}(t-\ell)\right] Y_{U}(t-\ell) \\
& V_{R}(t)=\bar{Y}_{R}(t-\ell)=\left[1-U_{R}(t-\ell)\right] Y_{R}(t-\ell) .
\end{aligned}
$$

Replacing the above in Eq. (10a), we obtain

$$
\frac{\tau_{U}}{S_{U}}(t)=F\left(\frac{\left[1-U_{U}(t-\ell)\right] Y_{U}(t-\ell)}{\left[1-U_{R}(t-\ell)\right] Y_{R}(t-\ell)}-1\right)
$$

Here, $S_{U}(t)$ is the existing size of the urban labor force, which is calculated as a product of labor participation rate and population in urban areas; $\tau_{U}(t)$ represents net rural-urban net migration $\mu_{R U} ; U_{U}(t), U_{R}(t)$ are unemployment rates in the urban area and the rural area, respectively. $Y_{u}(t)$ is net urban real income. $Y_{R}(t)$ is net rural real income. $F(\cdot)$ is an increasing function with $\mathrm{F}^{\prime}>0$. From here on we denote $\ell$ years lagged variables by superscript $\ell$. For example, $U_{U}(t-\ell)$ is denoted by $U_{U}^{\ell}$.
We update Eq. (10b) by replacing $\tau_{U}(t)$ by $\mu_{R U}$, replacing the normalizing variable $S_{U}(t)$ of the left hand side with labor supply in rural area $S_{R}(t)$ and replacing the normalizing variable of the argument of $\mathrm{F}(\cdot)$ with $\left(1-U_{U}^{\ell}\right) Y_{U}^{\ell}$, which means that the rates are made relative to rural variables

$$
\frac{\mu_{R U}}{S_{R}}=F\left(\frac{\left(1-U_{U}^{\ell}\right) Y_{U}^{\ell}-\left(1-U_{R}^{\ell}\right) Y_{R}^{\ell}}{\left(1-U_{U}^{\ell}\right) Y_{U}^{\ell}}\right)
$$

By multiplying $S_{R}$ on both sides, we have

$$
\mu_{R U}=\hat{F}\left(\frac{\left(1-U_{U}^{\ell}\right) Y_{U}^{\ell}-\left(1-U_{R}^{\ell}\right) Y_{R}^{\ell}}{\left(1-U_{U}^{\ell}\right) Y_{U}^{\ell}}\right)=\hat{F}\left(\eta^{\ell}\right),
$$

where superscript $\ell$ represent a lag of $\ell$ years and $\hat{F}(\cdot)$ is another increasing function since $S_{R}>0$.

Under the assumptions that, (1) the unemployment rate $U_{U}$ is much less than $U_{R}\left(U_{U}<<U_{R}\right)$ and close to 0 ; and (2) the migration prospect of rural population is not sensitive to income difference between rural and urban areas; Eq. (11b) transforms to

$$
\mu_{R U}=\tilde{F}\left(U_{R}^{\ell}-U_{U}^{\ell}\right)
$$

Where $\tilde{F}(\cdot)$ is another increasing function. We here note that Eq. (12) essentially assumes that migrants are being "pushed" to urban areas.

\section{Data series analysis}

We obtained hydro-meteorological time series from the Climate Research Unit (CRU, 1985-2015; Harris et al., 2014) and social data series from Bureau of Statistics, Jiangsu (1987-2016). We focus on the period from 1985 to 2013, which covers the period of Chinese economic reforms and where data was available. A detailed table for data resources is given in the Supplementary information A1.

Rural-urban net migration. In China, a population census (The State Council of The People's Republic of China, 2010) is taken every 10 years covering the entire country, during which data of population and migration are directly obtained by surveys. Meanwhile, every 5 years, sampling surveys (The State Council of The People's Republic of China, 2010) are carried out in order to estimate population-related data such as total and rural population. For the years in-between, these population time series can be obtained from estimates made by the Bureaus of Statistics of every province and every city. Here, cities and towns are classified as urban areas.

The official migration data for the Jiangsu province is "Migrating Population", which is available every 10 years. "Migrating Population" counts the number of people whose places of residence are different from where they had been registered. However, the "Migrating Population" only informs how many people have migrated and does not specify the origin or destination of migrants. In this study, we estimated a net migration time series of population flows from rural to urban areas using the time series of rural, urban and total population and natural population growth rate (see Eqs. (1)-(5c)). The estimated net migration from rural areas toward cities, $\mu_{R U}$, is shown in Fig. 3.

Figure 3 shows the net migration flow from rural to urban areas, which corroborates the narratives based on the five- 


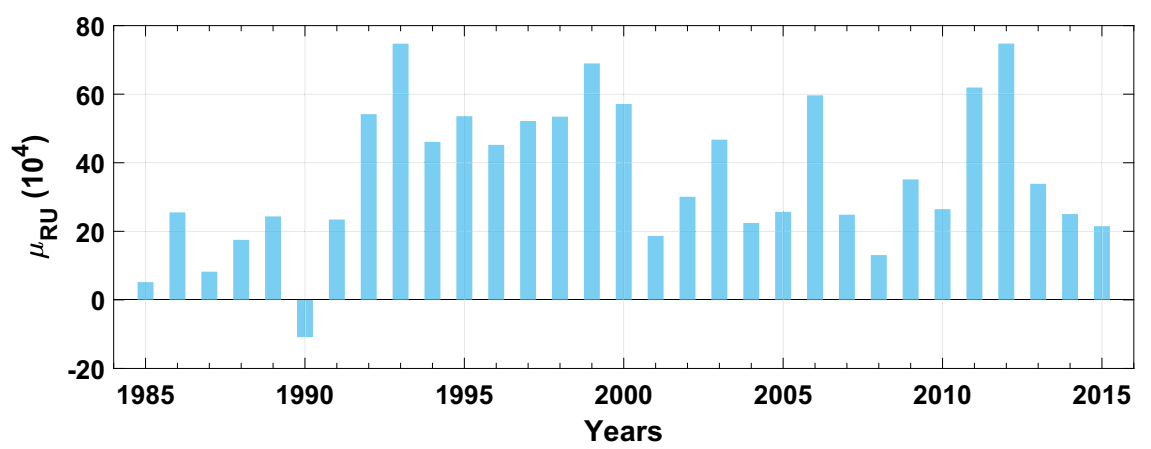

Fig. 3 The calculated time series of rural-urban net migration, $\mu R U$, based on Eqs. (1)-(5c)

(a)

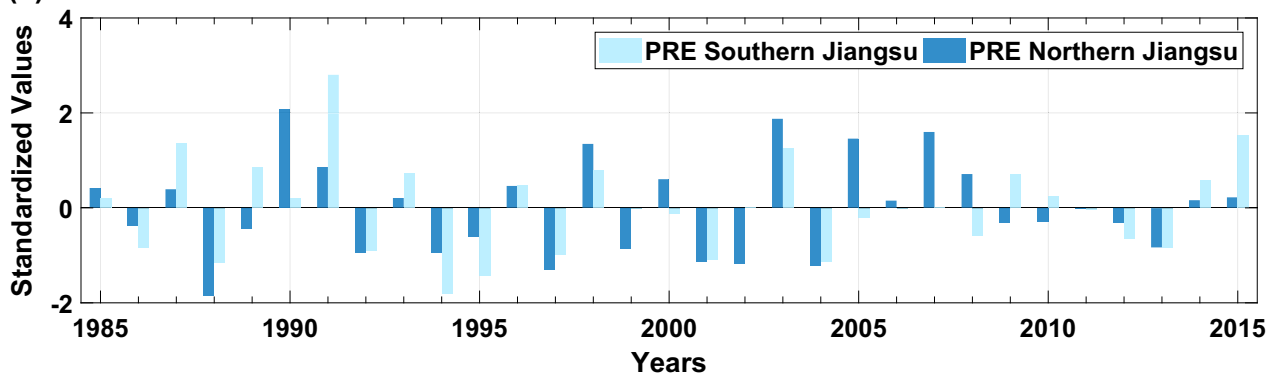

(b)

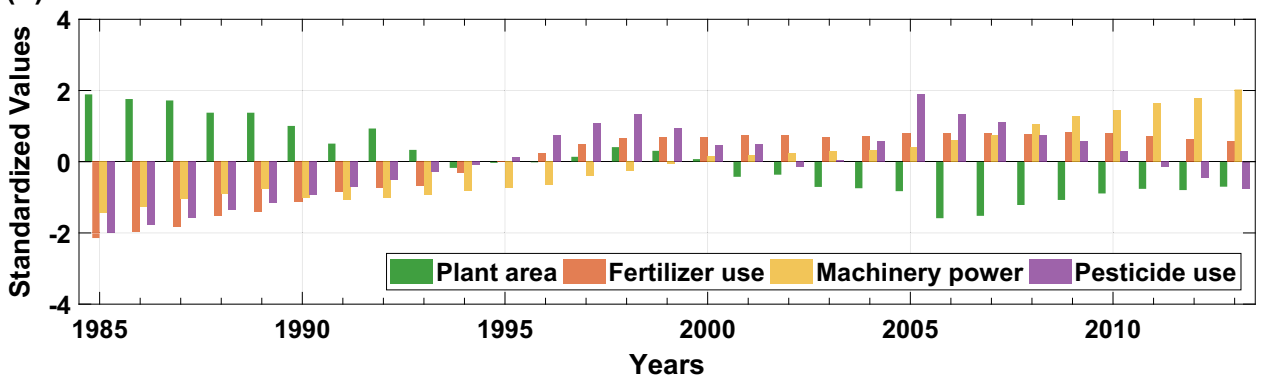

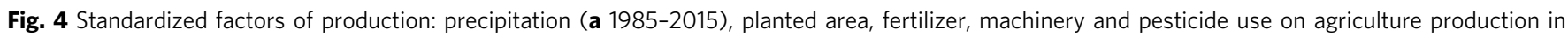
rural areas (b 1985-2013). The time series are standardized by subtracting the mean and dividing the time series by its standard deviation

yearly aggregate data where available. For example, net migration of people within the province from rural to urban areas during the $1986-1990$ period amounted to 650,000 (Jiangsu Provincial Local Chronicle Compilation Committee, 1999). This is close to the estimated net migration of around 64,700 (sum of migration values during this period). The first peak of rural-urban net migration occurred in the 1990s, overlapping with the period of large migration, followed by a decline in migration rates in the mid 2000s. The second peak occurred in the period from 2009 to 2014, which shows another boom in rural to urban migration.

Factors of production in rural agriculture. Sun et al. (2008) selected six factors, which included labor, planted area, irrigated area, fertilizer use, machinery power, and pesticide use, as the factors of rural agricultural production, and hence as the drivers of labor demand in the Cobb-Douglas production function, of the Nanjing province of China. The area of effective irrigation is already included in total planted area, and water availability may be represented by precipitation. Precipitation has a more significant impact on regional and temporal crop growth change within Jiangsu province than those of light and temperature
(Zhang et al., 2011). Therefore, we choose precipitation rather than irrigated area as one of the factors of agricultural production.

The standardized time series of all factors of agricultural production are shown in Fig. 4.

Figure $4 \mathrm{a}$ shows that the standardized precipitation in the northern and southern regions show similar patterns (precipitation in southern and northern Jiangsu are similar with each other with $R=0.56, p$-value $<0.001$. Southern-Jiangsu precipitation has been finally chosen as model input since it provides a better model performance). Long-term fluctuations occur over periods of 5-10 years. Figure $4 \mathrm{~b}$ shows other inputs to agricultural production. First, a decreasing trend of planted area can be observed. This indicates either shrinking or more land intensive rural agricultural production in Jiangsu. Fertilizer use increased from $\sim 1.5$ million tons in 1985 to $\sim 3.3$ million tons in 1998 and remained virtually constant over the remainder of the period, indicating that fertilizer use in agricultural production in Jiangsu province has reached a steady state. Machinery power rose gradually and steadily over the years, implying a steadily increasing reliance on agricultural mechanization. The use of pesticides has been declining since 2005. Figure 4a, b therefore suggest that agriculture output, and thus agricultural labor 
demand, remains susceptible to changes in rainfall in spite of heavy mechanization in recent years.

As described by the Cobb-Douglas production function $Y=$ $A \prod_{i=1}^{n} F_{i}^{\alpha_{i}}$ with $F_{i}$ as an input and $\alpha_{i}$ as its elasticity, the agricultural production depends only on its factors and how elastic agricultural production is in relation to these factors (Cobb and Douglas, 1928). Table 1 shows the elasticities corresponding to each of the factors of rural agricultural productivity, as provided by Sun et al. (2008). These elasticities were first estimated by Fan and Zhang (2002) for eight factors. Considering the data availability, Sun et al. (2008) further selected six of the nine factors, which covered $\sim 80 \%$ of the factors that contributed to agricultural production.

Among the factors selected by Fan and Zhang (2002), irrigated area was chosen to represent the influence of water availability during the process of crop cultivation. We replaced irrigated area with precipitation (Fig. 5).

Urban unemployment rate. The time series of urban unemployment rate, as shown in Fig. 5, was obtained from the official dataset of the Jiangsu province (Bureau of Statistics of Jiangsu, 1987-2016). The range of fluctuations in urban unemployment rate is much narrower than the modeled unemployment rate in rural areas since the labor market in urban areas is highly ordered. The boundary between employed and unemployed is clear in urban areas based on the registered population seeking employment.

Income Time Series. Figure 6 shows that rural income per capita, which remained steady between 1985 and 1994, began to rise slowly in 1995. This trend accelerated around 2005. However, the acceleration in urban income per capita was much earlier and much faster. A divergence between rural and urban income is evident. This can also be seen from the rural-urban income ratio that began to decline in late 1990s.

Figure 6 also shows the ratio of rural agricultural and nonagricultural income of Jiangsu (Bureau of Statistics of Jiangsu, 1987-2016). The divergence between these two sources of income in rural areas is much sharper. As shown in Fig. 6, the proportion of income from the agricultural sector in rural areas has decreased over time, which indicates the emergence of modern secondary and tertiary sectors such as manufacturing and services.

\section{Modeling results}

\section{Labor demand and unemployment}

Labor demand in rural agricultural and nonagricultural sectors. The calculated labor demands of the rural agricultural and nonagricultural sectors in the Jiangsu province are shown in Fig. 7 against surveyed (observed) data series from the Bureau of Statistics of Jiangsu (1987-2016). The comparison therefore assumes that the labor demand for efficient agricultural production is the same as labor employed, which may not always be the same. The unemployment calculated thereof considers all the labor that is not efficiently employed by agriculture. It therefore includes under-employed people as well. For example, more family members may on-record be employed in the family plot, which may require less workers for efficient production. Also, the rural labor force recorded may include people who work at other locations, but have not yet changed their household registrations (Jiangsu, 1987-2016).

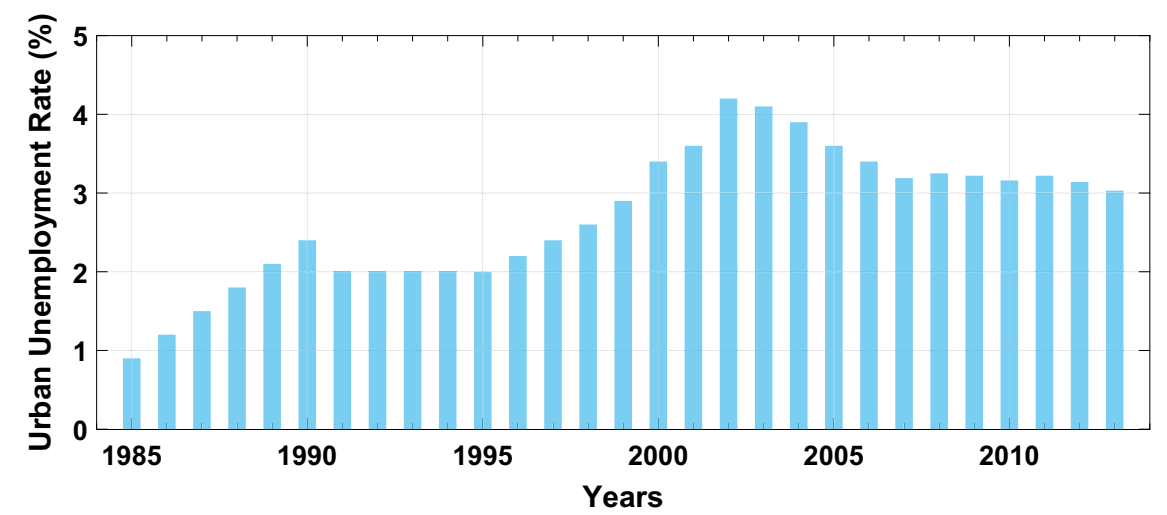

Fig. 5 Urban unemployment rate of Jiangsu Province, China: a steady increase until early 2000s can be observed where after it has stabilized

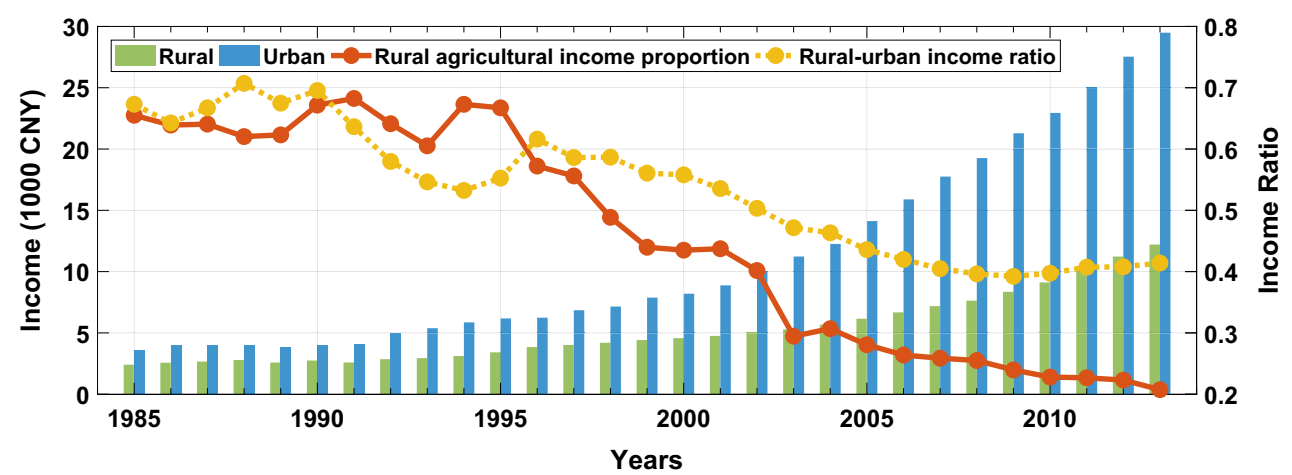

Fig. 6 (1) Rural and urban income per capita time series, (2) rural agricultural income as a proportion of average rural income (in red), and (3) rural to urban income per capita ratio $Y_{-} R / Y_{-} U$ (in yellow). Agricultural income relative to nonagricultural and urban income has been declining over time 


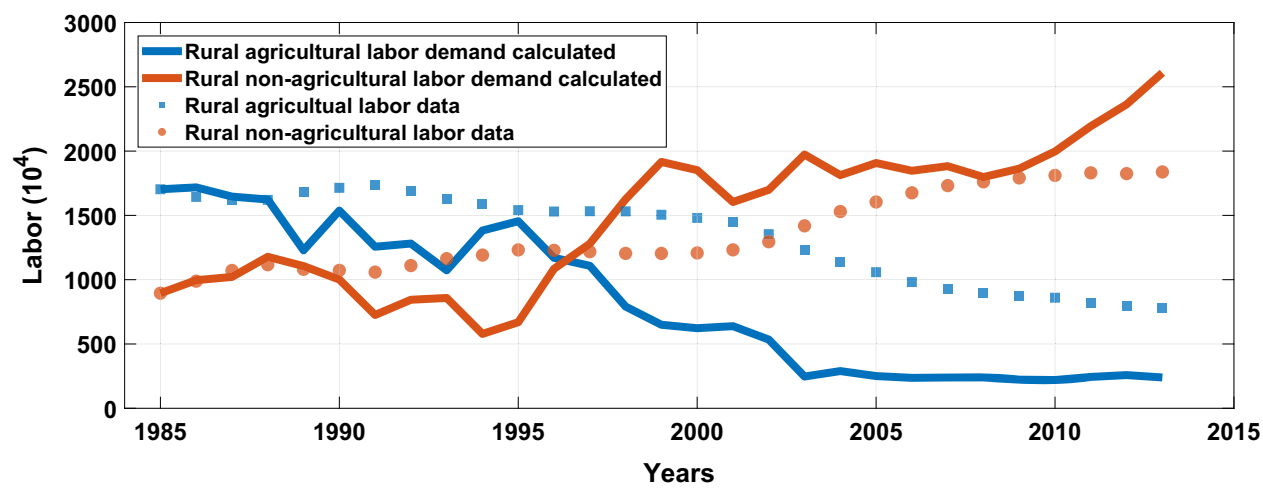

Fig. 7 Simulated labor demand in rural agricultural and nonagricultural sectors when compared to reported statistics. Underemployment in the agricultural sector is evident

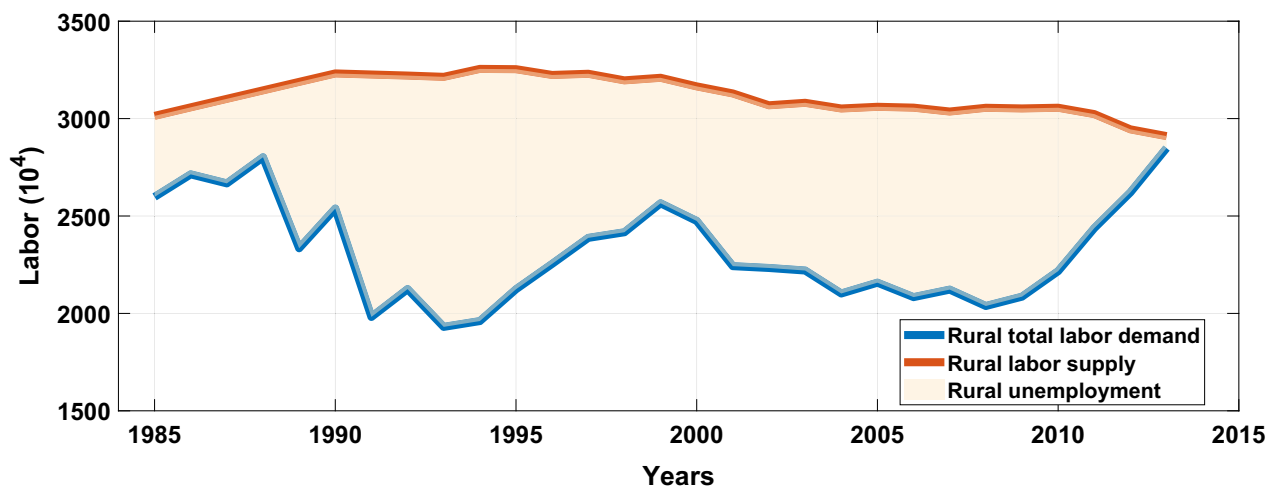

Fig. 8 Calculated rural total labor demand, rural labor supply and rural unemployment

Figure 7 shows that the rural agricultural labor kept decreasing while the number of nonagricultural laborers who worked in secondary and tertiary sectors rose over time. Since the rural labor supply remained relatively constant (see Fig. 8), this means that labor from traditional agricultural production either transferred to modern industries or emigrated. The estimated labor demand in the agricultural sector witnessed a sharp decline from 1997 to 2003, which was driven by a drop in agricultural income in the same period of time (Bureau of Statistics of Jiangsu, 1987-2016). According to the official report of Bureau of Statistics of Jiangsu in 2009 (Bureau of Statistics of Jiangsu, 2008), there was an increase in the price of agricultural inputs, with the prices of agricultural output remaining constant, thereby reducing net income from agricultural production during the period. This decline of agricultural net income led to a reduction of labor demand estimated by the Cobb-Douglas production function (Eq. (8c)).

The observed data series, obtained from official surveys of the Bureau of Statistics of Jiangsu (1987-2016), shows a similar pattern to the Cobb-Douglas-estimated labor demand, but differences are still evident. The number of rural agricultural laborers is stable over time, and the drop in agricultural income from 1997 to 2003 seems to not influence the observed amount of labor as much. The labor demand calculated by the Cobb-Douglas production function is labor needed for efficient production. However, more and more labor in rural areas obtain their incomes from different types of employment and thus are mostly underemployed, especially during lean years in agriculture. In official surveys, people who spend the largest proportion of their time in agriculture or obtain the largest portion of their income from agriculture are categorized as farmers. This means that most of the rural agricultural labor is not efficiently employed, especially in recent years that has witnessed expanding manufacturing and service sectors and dwindling returns from the agricultural sector. This explains why estimated rural nonagricultural demand follows the observed data more closely than rural agricultural labor demand, especially post 1995.

Rural unemployment. With the labor demand calculated using the Cobb-Douglas production function, we obtain the overall labor demand and unemployment for rural areas.

The total labor supply in rural areas of Jiangsu remained steady over the period between 1985 and 2013. Starting from 30 million people, labor supply rose slightly during the first decade and then gradually declined back to 30 million people in the 2010s.

Total rural labor demand, calculated by Cobb-Douglas production functions, however, underwent periodic fluctuations. It declined from the end of 1980s reaching its first minimum in 1993, then rose up to a peak in 1999. In the 2000s the labor demand declined again from $\sim 25$ million to $\sim 20$ million people in 2007. After 2007, the total labor demand again rose. The shaded area represents the gap between labor supply and labor demand in the rural areas of Jiangsu province and represents rural unemployment (including underemployed people not efficiently used in the agricultural sector). Nonetheless, inherent uncertainties in estimated total labor supply and demand may mean certain point estimates, such as close to zero unemployment in 2013, need closer scrutiny.

Rural-urban migration model. A linear function is applied to reveal the relationship, $\tilde{F}[$.$] in Eq. (12), between net migration \mu_{R U}$ and the unemployment gradient $U_{R}-U_{U}$. 

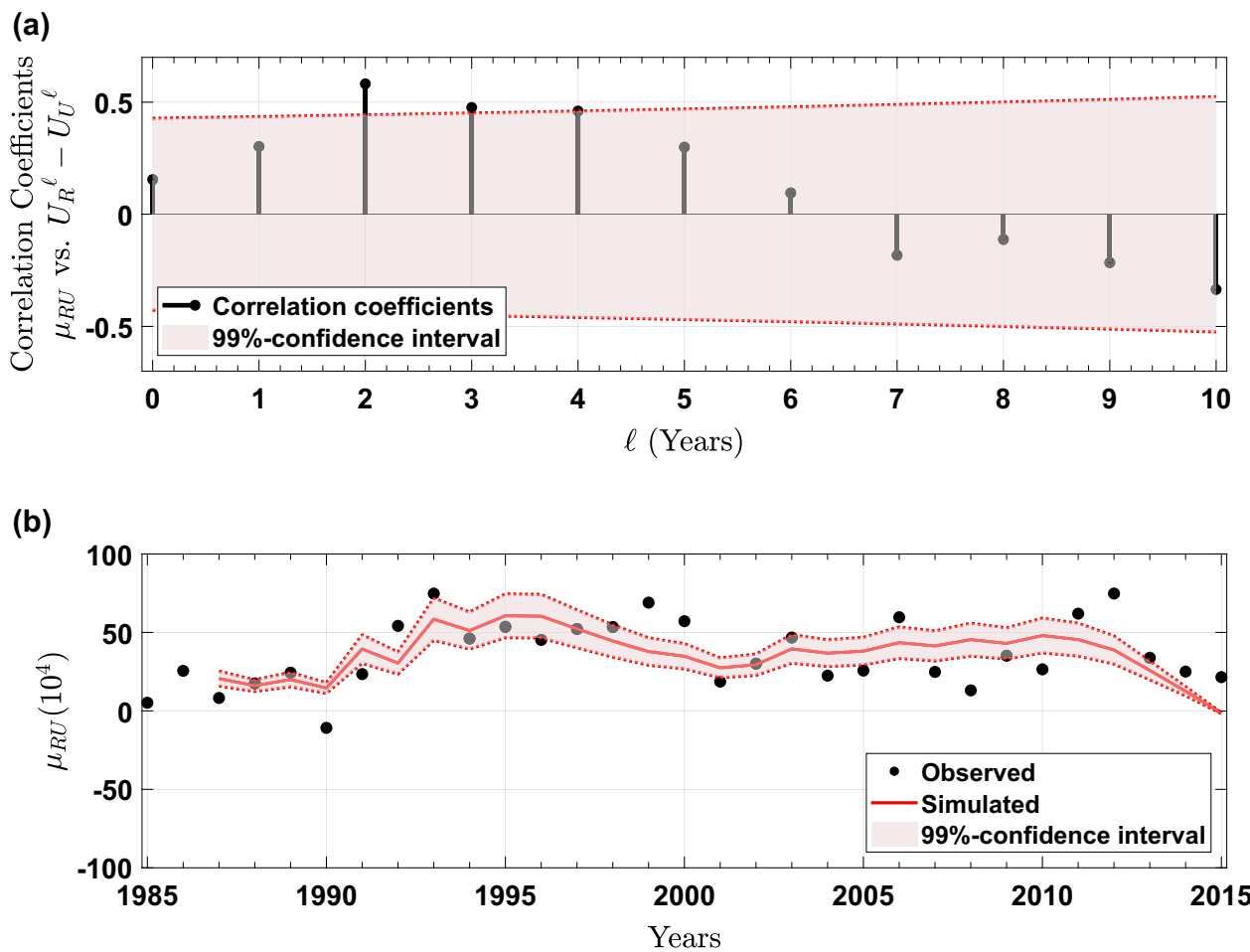

Fig. 9 a Correlation coefficients between rural-urban net migration and rural-urban unemployment gradient at different lags; $\mathbf{b}$ unemployment-driven rural to urban net migration simulated with 2 years lag. Shaded area shows $99 \%$ confidence interval. The observed migration data in $\mathbf{b}$ is the time series shown in Fig. 3

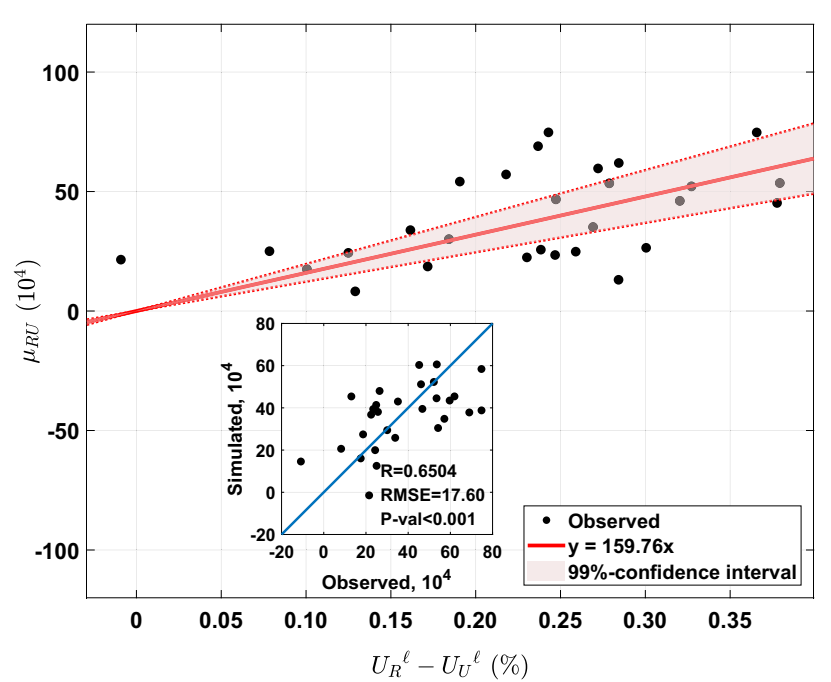

Fig. 10 Rural-urban net migration (1987-2015) as a linear function of rural-urban unemployment gradient (1985-2013) as hypothesized by Eq. 12. a the calibrated linear function in red with RMSE of 17.60 (104), $R=0.6504$ and $p$-value $<0.01$. $\mathbf{b}$ Time series of residuals between the observed and simulated migration time series and $\mathbf{c}$ the scatter plot of observed vs simulated migration

Figure 9a shows that a significant positive correlation exists between net migration and unemployment difference when the rural-urban unemployment gradient lags rural to urban net migration by $2-4$ years. This means that worsening rural unemployment condition takes $2-4$ years to impact migration flows. Another interpretation is that rural unemployed take between 2-4 years to decide and move to urban areas.
Figure $9 \mathrm{~b}$ shows the rural-urban net migration simulated by Eq. (12) shown in the red color, together with rural-urban net migration calculated from data series obtained from the Statistical Yearbook of Jiangsu (Bureau of Statistics of Jiangsu, 1987-2016) (based on Fig. 4). It shows a significant agreement between the observed and simulated time series, with the migration model explaining almost $65 \%$ of the variance in the observed time series (see Fig. 10, $R=0.65$ ). As Fig. 10 shows, the simulated time series of migration is based on a statistically significant relationship ( $p$ value $<0.001$ ) between rural-urban migration and the unemployment gradient. Its slope suggests that a $1 \%$ increase in rural unemployment can lead to the migration of an additional 16,000 people, on average, from rural to urban areas.

With a White Statistics of 0.199 , which is less than $\chi_{0.05}^{2}=5.99$ (degree of freedom is 2), the time series of residuals in the regression analysis is recognized as homoscedastic ( $\mathrm{Li}$ and Pan, 2010). The autocorrelation coefficients of residuals with lag of 1 and 2 years are $0.31(p$-value $=0.11)$ and $-0.17(p$-value $=0.39)$, respectively, which indicates that the residuals are not autocorrelated.

\section{Discussion}

Here we compare the linear migration model of Eq. (12) with six other linear models of rural-urban migration.

Correlations of migration with precipitation from 1985 to 2015 at Northern and Southern Jiangsu stations (shown in Fig. 1) are $-0.19(p$-value $=0.31)$ and $-0.15(p$-value $=0.43)$, respectively. This suggests that there is no clear direct signal of precipitation in migration time series at the provincial scale. Other studies in countries such as Bangladesh, Burkina Faso, and El Salvadore have found that even environmental shocks such as droughts, flooding, and even earthquakes do not necessarily trigger migration (Gray and Mueller, 2012; Chen et al., 2017). 
Table 2 Parameters and statistics of linear candidate models

\begin{tabular}{|c|c|c|c|c|c|c|}
\hline \multirow{3}{*}{$\begin{array}{l}\text { Parameters and } \\
\text { statistics }\end{array}$} & \multicolumn{6}{|c|}{ Linear models with different candidate driving factors } \\
\hline & 1 & 2 & 3 & 4 & 5 & 6 \\
\hline & $\mu_{R U} \sim \boldsymbol{U}_{R}^{\ell}-\boldsymbol{U}_{U}^{\ell}$ & $\mu_{R U} \sim \boldsymbol{U}_{R}^{\ell}$ & $\mu_{R U} \sim 1+V_{R}$ & $\mu_{R U} \sim \mathbf{1}+\eta^{\ell}$ & $\mu_{R U} \sim 1+\boldsymbol{U}_{U}^{\ell}$ & $\mu_{R U} \sim 1+\left(\boldsymbol{V}_{U}-\boldsymbol{V}_{\boldsymbol{R}}\right)+\Delta \boldsymbol{V}_{\boldsymbol{R}}$ \\
\hline$\beta_{1}$ ( $p$-value) & $159.76(<0.001)$ & $\begin{array}{l}144.97 \\
(<0.001)\end{array}$ & $-0.0010(0.557)$ & $82.604(0.030)$ & $169.01(0.722)$ & $-0.0012(0.439)$ \\
\hline$\beta_{2}(p$-value $)$ & - & - & - & - & - & $0.0064(0.221)$ \\
\hline$p$-value regression & $<0.001$ & $<0.001$ & 0.57 & 0.03 & 0.72 & 0.44 \\
\hline LL & -123.80 & -123.49 & - & -126.56 & - & - \\
\hline $\mathrm{BIC}$ & 250.97 & 250.35 & - & 259.86 & - & - \\
\hline
\end{tabular}

$\eta^{\ell}$ is the relative gradient in expected income shown on the right-hand side of Eq. (11b). $V_{U}$ and $V_{R}$, as introduced in "Unemployment-driven net migration", are expected income in urban and rural areas with unemployment rate considered; $\Delta V_{R}$ is a measure of volatility in past income, which is calculated as $\Delta V_{R}(t)=\left|V_{R}(t)-V_{R}(t-2)\right|+\left|V_{R}(t-2)-V_{R}(t-4)\right|$. "LL" refers to the log likelihood of each linear model, and "BIC" refers to the Bayesian information criterion. BIC amongst statistically significant models at $95 \%$ (models 1,2 , and 4 ) suggests that models 1 and 2 are best interpreters of rural to urban migration in Jiangsu province

However, a statistically significant relationship between migration and lagged rural unemployment suggests that climate variability may influence migration through unemployment alongside the influence of other inputs to rural production activities. Unemployment here is calculated as the percentage of labor supply that is not efficiently employed. It thus also includes the underemployed, unlike the official statistics. The second column (second candidate model) of Table 2 shows a linear regression with only the unemployment rate in rural area and the relationship (slope and significance level) suggests that migrants are not being "pulled" to urban areas, but instead are being "pushed" out of rural areas due to unemployment. Such observation is also corroborated by RUMiC 2007 and 2008 survey data for Jiangsu province (see Table S2 in supplementary materials), where in more than $60 \%$ of the respondents answered "push" related factors in response to "Why did you leave your rural hometown?" A dominant response had been "No future in hometown, do not like rural life-style", which is linked to unemployment or underemployment in rural areas $(22 \%$ in RUMiC 2008; $27 \%$ in RUMiC 2009). This was in spite of low levels of migration in 2007 and 2008 (Fig. 3). In order to further test if low income in rural areas plays a role, model 3 of Table 2 shows the regression of expected income in rural areas with migration. A poorer fit and lower R suggests that that model was a poorer interpreter of migration statistics. Table 2, models 4 and 5 also show linear regression of $\mu_{R U}$ with $\eta^{\ell}$ (i.e., relative gradient in expected income) and unemployment in urban areas, respectively. Both are insignificant at the $99 \%$ confidence level suggesting that "pull" factors are not detectable at the Jiangsu province scale using the time series over the selected period. Model 6 of Table 2 further shows that neither urban to rural gradient in expected income nor income volatility in rural area appear to influence rural to urban migration.

In response to the question "Have you been back to your home village for longer than 3 months after migrating to the city?" 86.9 and $91.9 \%$ of rural to urban migrants have not been back to their home village for longer than 3 months in 2007 and 2008, respectively, which means most migrants in Jiangsu are not temporary migrants (Table S3 in supplementary materials). Furthermore, in response to the question "If you were still in your home village, how much do you estimate you could earn every month?", a median answer of $\sim 800 \mathrm{CNY} /$ month was given (Table S4 in supplementary materials). According to the statistical yearbook of the Jiangsu province, achieving a monthly total income of $800 \mathrm{CNY}$ per month, i.e., $9600 \mathrm{CNY}$ per year, is above the average income level of rural population (8119.5 CNY in 2007 and 9092.8 CNY in 2008). This indicates that the migrants in Jiangsu are not the poorest in rural areas.

The statistically significant relationships between migration and unemployment (and not rural or urban income) corroborates with RUMiC data that migration within the Jiangsu province is likely to be occurring due to poorer employment opportunities in rural areas in spite of the possibility of earning above average income. Given that the decision to migrate is difficult and has costs associated with it, several studies have found that migrants tend not to be poorest and are often driven by under/unemployment (Chen et al., 2019; Massey et al., 1993). This likely explains the lack of sensitivity of migration to the income gradient over time.

We generated a migration time series for Jiangsu province based on diverse socio-economic data sets for the first time. This allowed us to not only investigate its sensitivity to unemployment or income gradients, but also to any changes in income over lagged time periods (as a measure of volatility). Statistically significant correlation between lagged unemployment and migration suggests that a window of 2-4 years after experiencing unemployment is crucial. This is based on the notion that humans form expectations based on past events (see Eq. (10b)). Thus, high unemployment is enough to trigger a farmer to decide to migrate in the next 2-4 years, irrespective of whether he or she will earn better or worse living in urban areas. This suggests that households appear to wait for 2-4 years, possibly reflecting on the social costs of migration before migrating. Further, such decisions do not appear to be sensitive to changes in rural income over lagged periods (Table 2) further indicating that rural-urban migration in Jiangsu provide is pushed by unemployment in rural areas, often undertaken by relatively rich who appear sensitive neither to maximizing their household income nor minimizing income risk.

Rural to urban migration in the Jiangsu province is a transfer of labor from mostly primary employment in rural areas to secondary and tertiary employment in urban areas. Figure 10 shows that a $1 \%$ contraction in rural labor demand can result, on average, in 16,000 more people migrating from rural to urban areas at Jiangsu provincial scale. Given that migrants appear to experience 2-4 years of unemployment before migrating, provincial or local governments have some lead time to prepare for a migrant wave. A shock in rural employment may appear due to shocks in input prices of fertilizers or machinery, of agricultural outputs or extreme drought conditions. Such shocks thus may be 
considered as predictive triggers of above normal rural to urban migration.

\section{Conclusions}

This paper interpreted rural-urban migration in the Jiangsu province of China for the last 30 years. The net migration flow from rural to urban areas was analyzed together with rural and urban unemployment rates and incomes in order to unravel the underlying mechanisms.

The labor demands in rural agricultural and nonagricultural sectors were estimated based on Cobb-Douglas production functions. Simulations showed that rural agricultural labor demand declined quickly around 1995, as a result of rising input prices. Its comparison with the official surveyed data of rural labor indicated that many in rural areas whom officially registered employed in the agricultural sector were underemployed. Such rural underemployment was therefore implicitly considered in the estimated rural unemployment when interpreting rural to urban migration.

We found that migration from rural to urban areas was sensitive to rural unemployment rate lagged by $2-4$ years. However, our analysis was unable to detect any significant correlation between migration and precipitation anomalies, urban employment or income (neither rural nor urban), or volatility in rural income. Also corroborated by RUMiC 2007 and 2008 surveys, this thus suggests that rural to urban migration in Jiangsu is a result of rural unemployment (and underemployment) that is pushing rural residents to urban areas. Economic or employment shocks that lead to unemployment may therefore be considered as predictive triggers of above normal rural to urban migration since a $1 \%$ increase in such unemployment can push, on average, 16,000 people from rural to urban areas within 2-4 years.

\section{Data availability}

The datasets analyzed in the study are listed in the supporting information. The datasets generated in the current study and plotted in the figures are available in the Dataverse repository: https://doi.org/10.7910/DVN/BJWIOB

Received: 18 February 2019 Accepted: 16 July 2019

Published online: 13 August 2019

\section{References}

Akay A, Bargain O, Zimmermann KF (2012) Relative concerns of rural-to-urban migrants in China. J Econ Behav Organ 81(2):421-441. https://doi.org/ 10.1016/j.jebo.2011.12.006

Barrios S, Bertinelli L, Strobl E (2006) Climatic change and rural-urban migration: the case of sub-Saharan Africa. J Urban Econ 60(3):357-371. https://doi.org/ 10.1016/j.jue.2006.04.005

Black R, Adger WN, Arnell NW, Dercon S, Geddes A, Thomas D (2011) The effect of environmental change on human migration. Glob Environ Change 21: S3-S11. https://doi.org/10.1016/j.gloenvcha.2011.10.001

Bryan G, Chowdhury S, Mobarak AM (2014) Underinvestment in a profitable technology: the case of seasonal migration in Bangladesh. Econometrica 82 (5):1671-1748. https://doi.org/10.3982/ECTA10489

Bureau of Statistics of Jiangsu (1987-2016) Statistical yearbook of Jiangsu. China Statistics Press. http://ti.jiangsu.gov.cn/col/col64418/index.html

Bureau of Statistics of Jiangsu (2008) Farmers' life from poverty to all-round moderate prosperity. Bureau of Statistics of Jiangsu. http://tj.jiangsu.gov.cn/ art/2008/10/30/art_4028_2273367.html

Chen C, Wu Y (2010) Research on correlation between total factor productivity and capital together with labor input: an empirical analysis based on Jiangsu Province. Mod Manag Sci 2010(9):44-45. https://doi.org/10.3969/j.issn.1007368X.2010.09.016

Chen J (2007) Discussion on the relevant relations between population flow and employment. J Anhui Agric Sci 35(36):12065-12067. https://doi.org/10.3969/ j.issn.0517-6611.2007.36.156
Chen J (2009) An empirical study on the issue of rural 'empty nest' elders in economically developed areas: a case study of rural areas in Suzhou. China Rural Surv 2009(4):47-56

Chen J, Kosec K, Mueller V (2019) Moving to despair? Migration and well-being in Pakistan. World Dev 113:186-203. https://doi.org/10.1016/j.worlddev. 2018.09.007

Chen JJ, Mueller V, Jia Y, Tseng SKH (2017) Validating migration responses to flooding using satellite and vital registration data. Am Econ Rev 107 (5):441-445. https://doi.org/10.1257/aer.p20171052

China Institute for Income Distribution, Beijing Normal University (2019) CHIP dataset. China Institute for Income Distribution, Beijing Normal University. http://www.ciidbnu.org/chip/

Cobb CW, Douglas PH (1928) A theory of production. Am Econ Rev 18 (1):139-165

CRU (1985-2015) CRU TS4.01: Climatic Research Unit (CRU) Time-Series (TS) version 4.01 of high-resolution gridded data of month-by-month variation in climate (Jan 1901-Dec 2016). https://crudata.uea.ac.uk/cru/data/hrg/

Duan C, Zhou F (2005) Research on the situation of left-behind children in China. Popul Res 29(1):29-36. https://doi.org/10.3969/j.issn.1000-6087.2005.01.004

Fan S, Zhang X (2002) Production and productivity growth in Chinese agriculture: New national and regional measures. Econ Dev Cult Change 50(4):819-838

Fisher, FM (1962) A priori information and time series analysis: essays in economic, theory and measurement. Amsterdam, The Netherlands, p 168

Glomm G (1992) A model of growth and migration. Can J Econ 25(4):901-922. https://doi.org/10.2307/135771

Goldsmith PD, Gunjal K, Ndarishikanye B (2004) Rural-urban migration and agricultural productivity: the case of Senegal. Agric Econ 31(1):33-45. https:// doi.org/10.1111/j.1574-0862.2004.tb00220.x

Gray CL, Mueller V (2012) Natural disasters and population mobility in Bangladesh. Proc Natl Acad Sci 201115944. https://doi.org/10.1073/pnas.1115944109

Harris IPDJ, Jones PD, Osborn TJ, Lister DH (2014) Updated high-resolution grids of monthly climatic observations-the CRU TS3. 10 Dataset. Int J Climatol 34 (3):623-642. https://doi.org/10.1002/joc.3711

Huang R (2006) The quantity of the flowing population and analysis on its characteristic of distribution-based on the cases of jiangsu Province. Northwest Popul J 108(2):15-18

Jiangsu Provincial Local Chronicle Compilation Committee (1999) Local Chronicle of Jiangsu Population Chronicle

Knight J, Gunatilaka R (2010) The rural-urban divide in China: Income but not happiness? J Dev Stud 46(3):506-534. https://doi.org/10.1080/ 00220380903012763

Li B (2010) Study on cultural conflicts and integration of rural population inflows into cities in the New Era. Paper presented at The New Round of Western Development and Social Development in Guizhou, Guizhou, China

Li G (2010) Industrial TFP growth and industry difference in Jiangsu Province: 2002-2008-industry analysis based on DEA-Malmquist. Market Weekly $8: 22-24$

Li Z (2005) Population movement and urban conflict. China Reform 2005 (9):67-68

Li Z, Pan W (2010) Econometrics (3rd Version). Higher Education Press, Beijing, China, 113

Lilleør HB, Van den Broeck K(2011) Economic drivers of migration and climate change in LDCs. Glob Environ Change 21:S70-S81. https://doi.org/10.1016/j. gloenvcha.2011.09.002

Liu H, Yan J, Ma Y (2010) Study on features of rural population migration in Jiangsu. Stat Sci Pract 6:25-27. https://doi.org/10.3969/j.issn.16748905.2010.06.009

Liu Y, Shen J (2017) Modelling skilled and less-skilled interregional migrations in China, 2000-2005. Popul Space Place 23(4):e2027. https://doi.org/10.1002/ psp. 2027

Mabogunje AL (1970) Systems approach to a theory of rural-urban migration Geogr Anal 2(1):1-18. https://doi.org/10.1111/j.1538-4632.1970.tb00140.x

Massey DS, Arango J, Hugo G, Kouaouci A, Pellegrino A, Taylor JE (1993) Theories of international migration: a review and appraisal. Popul Devel Rev 431-466. https://doi.org/10.2307/2938462

McLeman RA, Hunter LM (2010) Migration in the context of vulnerability and adaptation to climate change: insights from analogues. Wiley Interdiscip Rev: Clim Change 1(3):450-461. https://doi.org/10.1002/wcc.51

Munshi K, Rosenzweig M (2016) Networks and misallocation: Insurance, migration, and the rural-urban wage gap. American Econ Rev 106(1):46-98. https://doi.org/10.1257/aer.20131365

National Bureau of Statistics of China (2016) China Statistical Yearbook. China Statistics Press. http://www.stats.gov.cn/tjsj/ndsj/

Pande S, Ertsen M, Sivapalan M (2014) Endogenous technological and population change under increasing water scarcity. Hydrol Earth Syst Sci 18 (8):3239-3258. https://doi.org/10.5194/hess-18-3239-2014

Pissarides CA, Wadsworth J (1989) Unemployment and the inter-regional mobility of labour. Econ J 99(397):739-755. https://doi.org/10.2307/2233768 
Roobavannan M, Kandasamy J, Pande S, Vigneswaran S, Sivapalan M (2017a) Allocating environmental water and impact on basin unemployment: role of a diversified economy. Ecol Econ 136:178-188. https://doi.org/10.1016/j. ecolecon.2017.02.006

Roobavannan M, Kandasamy J, Pande S, Vigneswaran S, Sivapalan M (2017b) Role of sectoral transformation in the evolution of water management norms in agricultural catchments: a sociohydrologic modeling analysis. Water Resour Res 53(10):8344-8365. https://doi.org/10.1002/2017WR020671

Schmalensee R (1976) An experimental study of expectation formation. Econometrica 44(1):17-41

Shen J, Spence NA (1996) Modelling urban-rural population growth in China. Environ Plan A 28(8):1417-1444. https://doi.org/10.1068/a281417

Sun X, Fan J, Hu H (2008) Regional agricultural TFP measurement and decomposition of China: based on empirical analysis of Nanjing City. Technol Econ 27(1):73-79. https://doi.org/10.3969/j.issn.1002-980X.2008.01.014

Tacoli C (2009) Crisis or adaptation? Migration and climate change in a context of high mobility. Environ Urban 21(2):513-525. https://doi.org/10.1177/ 0956247809342182

The State Council of The People's Republic of China. National Population Census Regulations (2010) http://gjdc.gd.gov.cn/fgzd/zcfg/201703/t20170306_147150. html

Thomas B (1973) Migration and economic growth: a study of Great Britain and the Atlantic economy (Vol. 12): CUP Archive. London, The United Kingdom, 35-55.

Todaro MP (1969) A model of labor migration and urban unemployment in less developed countries. Am Econ Rev 59(1):138-148

Wang X (2017) Analysis of regional characteristics and influencing factors of population migration of Jiangsu Province. Master thesis, Party School of C.P.C. Jiangsu Committee, http://kns.cnki.net/KCMS/detail/detail.aspx?dbcode= CMFD\&dbname $=$ CMFD201801\&filename $=1017211395$.nh\&uid $=$ WEEvREc wSIJHSIdRa1FhdkJkVWI0QVRGZ2Q4dGR6a1JpOEx0dTFhRVhkVT0=\$9A4 hF_YAuvQ5obgVAqNKPCYcEjKensW4IQMovwHtwkF4VYPoHbKxJw!! $\& \mathrm{v}=$ MDI0MDRHYkc1SDIMRnFwRWJQSVI4ZVgxTHV4WVM3RGgxVDN xVHJXTTFGckNVUkxLZmIrWm1GeTduVUx6QlZGMjY=

Wang X, Luo X (2014) Research on climate damage and migration issues of destitute rural populations: a preliminary research framework. Popul J 36 (3):63-70. https://doi.org/10.3969/j.issn.1004-129X.2014.03.007

Xu G (2009) Rural population development and new rural. Constr Popul Soc 25 (2):5-11. https://doi.org/10.3969/j.issn.1007-032X.2009.02.001

Yan D, Shi G (2017) Population migration and adaptation to climate change: western disputes and China's practice. J Chengdu Univ Technol (Soc Sci) 25 (1):69-76. https://doi.org/10.3969/j.issn.1672-0539.2017.01.013

Yao Y (2006) The issue of providing for rural 'empty nest' elders in economically developed areas: a case study of rural areas in Zhejiang. Popul Res 30 (6):38-46. https://doi.org/10.3969/j.issn.1000-6087.2006.06.005

Yu Q, Shi G, Chen S (2011) Climate change migration: extreme climate events and adaptation survey on rural migration in Southwest China in the 2010 severe drought. China Popul Resour Environ 21(8):29-34. https://doi.org/10.3969/j. issn.1002-2104.2011.08.005
Zhang H, Zhou S, Wu S, Zheng G, Hua S, Li L (2011) Temporal and spatial variation of grain production in Jiangsu Province and its influencing factors. J Nat Resour 26(2):319-327. https://doi.org/10.11849/zrzyxb.2011.02.015

Zhang J, Huang Y (2009) Current situations and countermeasures of population flow and its social insurance in Jiangsu. Prices Mon 382(3):45-47. https://doi. org/10.3969/j.issn.1006-2025.2009.03.014

Zhang KH, Shunfeng S (2003) Rural-urban migration and urbanization in China: evidence from time-series and cross-section analyses. China Econ Rev 14 (4):386-400. https://doi.org/10.1016/j.chieco.2003.09.018

Zhao Y (1999) Leaving the countryside: rural-to-urban migration decisions in China. Am Econ Rev 89(2):281-286. https://doi.org/10.1257/aer.89.2.281

Zhou F, Duan C (2006) A review of researches on left-behind children. Popul J 157 (3):60-64. https://doi.org/10.3969/j.issn.1004-129X.2006.03.012

\section{Acknowledgements}

Thanks are due to Nathan Hatch for his comments on the paper. The authors are solely responsible for any errors or omissions that may remain.

\section{Additional information}

The online version of this article (https://doi.org/10.1057/s41599-019-0302-1) contains supplementary material, which is available to authorized users.

Competing interests: The authors declare that they have no competing interests.

Reprints and permission information is available online at http://www.nature.com/ reprints

Publisher's note: Springer Nature remains neutral with regard to jurisdictional claims in published maps and institutional affiliations.

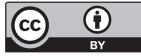

Open Access This article is licensed under a Creative Commons Attribution 4.0 International License, which permits use, sharing, adaptation, distribution and reproduction in any medium or format, as long as you give appropriate credit to the original author(s) and the source, provide a link to the Creative Commons license, and indicate if changes were made. The images or other third party material in this article are included in the article's Creative Commons license, unless indicated otherwise in a credit line to the material. If material is not included in the article's Creative Commons license and your intended use is not permitted by statutory regulation or exceeds the permitted use, you will need to obtain permission directly from the copyright holder. To view a copy of this license, visit http://creativecommons.org/ licenses/by/4.0/.

(c) The Author(s) 2019 